\title{
Main reasons to modify the ecomonitoring system of Novomoskovsk atmosphere relying on modern modeling methods
}

\author{
Grinyuk Olga ${ }^{1, *}$, Aleksashina Olga ${ }^{2}$, Arkhipov Alexander ${ }^{3}$, Ganesan Catherine ${ }^{4}$ \\ ${ }^{1}$ Novomoskovsk Institute of the Russian Chemical Technology University, Novomoskovsk, \\ Russia \\ ${ }^{2}$ Moscow Polytechnic University, Moscow, Russia \\ ${ }^{3}$ Tula State University, Tula, Russia \\ ${ }^{4}$ Administration of the city's municipal education of Novomoskovsk, Novomoskovsk, \\ Russia
}

\begin{abstract}
Novomoskovsk is one of the main centers of chemical industry in central Russia. In 2000 to control and monitor the region air quality and movement the atmosphere ecomonitorin system was created. These systems' modifying lies in using more sophisticated technology, increasing number of observation stations and automatic sensors that determine harmful impurities. The data adequacy of airspace's state hinges on the number of these stations and their location. The objective of our study is to estimate the data adequacy relying on modern research methods. The research involved the interpolation method of air movement control over areas which have a mixed landscape because of technology-related accidents. The method consists of 3 main stages: experimental examination of the area's weather conditions, processing of this data using the method of air flow field recovery, and effective control of the air dynamics at man-made accidents. Air control stations gave the initial measures and current data to develop the method of air flow field recovery on the basis of the noise-resistant interpolation principle. Noise-resistant interpolation admits to errors of measuring instruments, which makes a significant magnitude when estimating meteorological data of the air. The data obtained requires to modify Novomoskovsk ecomonitoring system of the atmosphere.
\end{abstract}

\section{Introduction}

*Corresponding author: olgrinyuk@mail.ru 
Novomoskovsk is one of the main centers of chemical industry in central Russia that includes such large organizations as NAK «Azot», «Procter \& Gamble - Novomoskovsk», OOO «Orgsintez», OOO «Polyplast Novomoskovsk». These companies increase output annually. This industrial cluster is a potential spot for technology-related accidents, when highly toxic substances erode the atmosphere. In 2000 to control and monitor the region air quality and movement the atmosphere ecomonitoring system was created. With growing industry the demand to scrutinize the settlement's air condition is gaining momentum. Nowadays more innovative systems of air pollution control are used. There is growing number of monitoring stations and automatic sensors that determine harmful impurities. It's relevant to justify the certain number of stations and their location as they contribute to the data adequacy.

The main goals and objectives of the ecomonitoring system of the city are the following [5,9]:

- $\quad 24 / 7$ monitoring of the air quality and movement over the city;

- automatic measurement and concentrations recording of six pollutants;

- the ecomonitoring data fund forming;

- $\quad$ providing compelling data to Civil Defence Service and Services for Emergency Situations in case of technology-related accidents in order to project possible implications, taking into account the size and movement of the gas cloud;

- informing citizens on the current air condition;

Novomoskovsk ecomonitoring system includes an automatic control system "Atmosfera» and Roshydromet Stations. Roshydromet stations are located in the Northern district (Station No. 1), the Central part of the city (Station No. 2) and Vakhrushevsky district (Station No. 3).

The system of Novomoskovsk automatic control system "Atmosfera" has been operated since 2000. Collecting, processing and presenting of information on the level of the city's air pollution is carried out automatically at 20 minutes intervals. The obtained data are passed to the MCM "UDDS" and to the administration of Municipal Novomoskovsk education to analyze take effective measures. Yet it is displayed on the administration website in real time.

FRC «Atmosfera» processes and analyzes the information collected on six main substances (nitrogen dioxide, nitrogen oxide, ammonia, carbon monoxide, sulfur dioxide, hydrogen sulphide) $[3,4]$ from four stationary stations which are located in different city areas. The list of measured substances is determined considering the requirements established by RD 52.04.186-89 «Guidance on air pollution control» and GOST 17.2.3.0186 «Nature Protection. Atmosphere. Rules of settlements' air quality control»[1, 2].

According to points 2.5 and 2.7 of the mentioned GOST, the number of stations and their location is determined considering the population, the settlement's area and the terrain, as well as the industry developing. In settlements one stationary or route station is established through each $0,5-5 \mathrm{~km}$ taking into account whether the considerable number of pollution sources is available, as well as the relief complexity [1].

Nowadays there are four operating stations FRC Atmosfera in Novomoskovsk, but their location fails to meet the all GOST 17.2.3.01-86 requirements. These rules suggest that each station, despite the category should be located in an open, ventilated area with a non-dusting coating: asphalt, hard ground, lawn as greenery, buildings can affect compelling measurement results [2].

The location of three stations FRC «Atmosfera» was chosen about 20 years ago on the basis of certain opportunities rather than GOST requirements. Thus, all measurement points of ecomonitoring system are located in residential area (Fig. 1) 


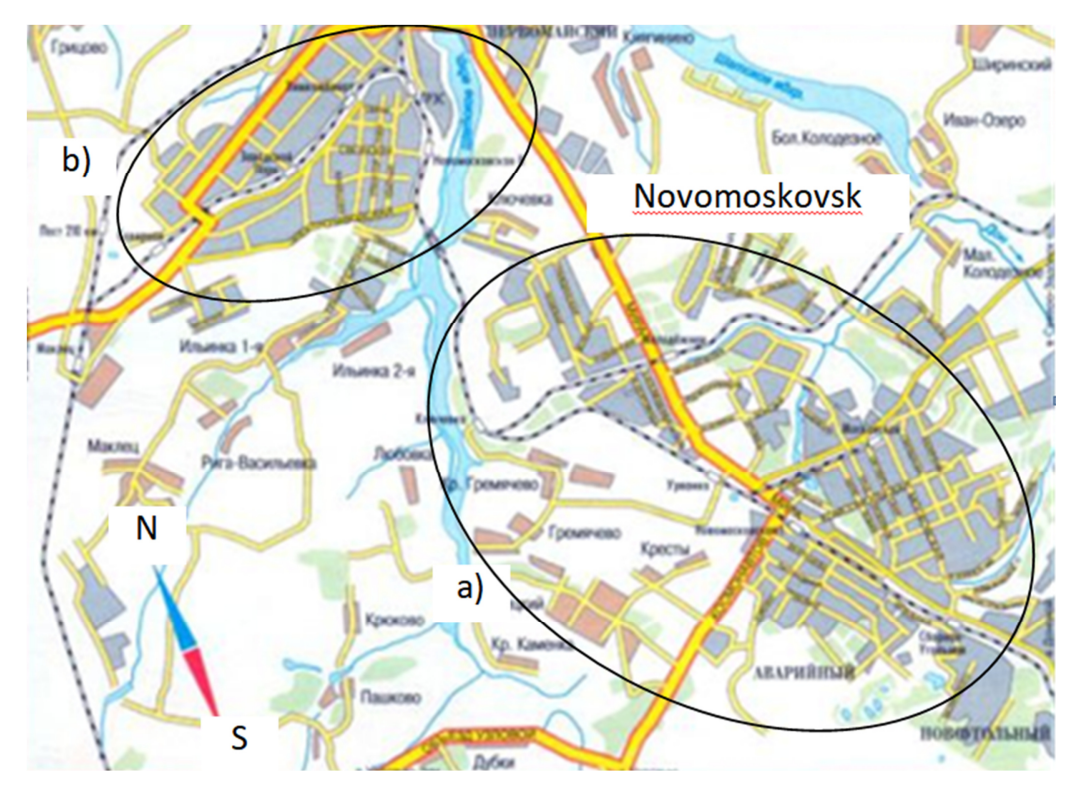

Fig. 1 The map of Novomoskovsk city (a- industrial area, b -residential area)

However, the main industrial cluster, which includes the largest chemical organizations of the city, is located behind the Lyubov reservoir. It is about 4 kilometers away from the nearest residential area (Gipsovy) and about 6 kilometers from the Northern district where the nearest Roshydromet station and FRC «Atmosfera» station that track the main weather conditions is situated. Yet, this site has a mixed landscape, which consists of a quite large water body for this area - the Lubovskoye reservoir. The question is: will the nearest monitoring stations' data show an accurate picture of air over the industrial cluster? For this purpose, we have conducted experimental and theoretical research using the simulation.

The objective of our study is to estimate the data adequacy relying on modern research methods.

- Detailed description of methods and scheme of experiments / observations, allowing to reproduce their results, using only the text of the article;

- Description of materials, equipment and other conditions of experiments.

\section{Materials and Methods}

Meteorological data on the district air environment is monitored by Roshydromet stations, but these are the data that help estimate the situation around the whole Novomoskovsk area in case of technology-related accident. Therefore it was relevant to select the sample of defining measurment points: three of them, correspond to Roshydromet stationary laboratories, and a point on the industrial district territory. Measurements were carried out three times a day along with the control stations. By manual control means: anemometer and compass. Two workers made the sample, one of them was in an industrial area, and the other in the residential city's area, moving between spots by vehicles for a few minutes, to obtain well-grounded data. Three affordable anemometers MEGEON-11030 were chosen to take measurements. This is a high-precision anemometer with integrated weather vane which has the following features. 


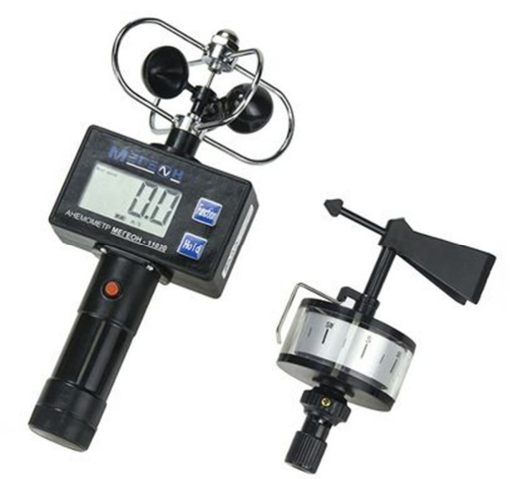

Fig. 2. The anemometer MEGENON-11030 wrapping

Table 1. The anemometer MEGENON-11030 specifications:

\begin{tabular}{|c|c|}
\hline Options & Values \\
\hline Wind speed measuring rage & $0 \sim 30 \mathrm{~m} / \mathrm{s}$ \\
\hline $\begin{array}{l}\text { The margin of indication error } \text { u the limit } \\
\text { of ultimate wind speed } V \text { or }\end{array}$ & $\begin{array}{c}\text { at most } \pm(0,3+0,03 \mathrm{~V}) \mathrm{m} / \mathrm{s}, \mathrm{V} \text { - measured } \\
\text { speed }\end{array}$ \\
\hline Wind direction & \\
\hline Wind direction measuring rage & $0 \sim 360^{\circ}$ \\
\hline
\end{tabular}

We used interpolation method of air traffic control areas with the mixed terrain in technology-related accidents as a theoretical research method on the basis of the gas cloud movement simulation. The research involved the interpolation method of air movement control over areas which have a mixed landscape because of technology-related accidents. The method consists of 3 main stages: experimental examination of the area's weather conditions, processing of this data using the method of air flow field recovery, and effective control of the air dynamics at technology-related accidents. Air control stations gave the initial measures and current data to develop the method of air flow field recovery on the basis of the noise-resistant interpolation principle. Noise-resistant interpolation is stable to errors of measuring instruments, which makes a significant value when estimating meteorological data of the air basin.

To obtain well-grounded information on the spatial and temporal air flow variability, it is necessary to conduct preliminary experimental surveys of the area meteorological condition using mobile means. The survey methodology is the following: routes traffic to measure the direction and speed of the wind at defining points on the terrain map are selected so that each plot area can be examined in a short time, thus to obtain compelling results.

Multiple defining point measurements of wind speed and direction given different weather conditions are carried out in the survey area (Fig. 1) to set out experimental statistical material on the air movement. Then the data are processed by noise-resistant interpolation (Fig. 4) and vector fields of the air flow direction and speed are built. The main advantage of noise-resistant interpolation is that it is stable to errors of the used measuring equipment, which in wind direction and speed measuring instruments are very significant.

To visualize direction and speed distribution of air flows fields it is necessary to create air flow diagrams(b). When you overlay the fields of the direction and air flow speed values on the area map, we get a plot, which help us to observe the direction in which the air flow moving, at each point of the surveyed area under current weather conditions[7]. 
Table 2. The varying shows heterogeneous values allocation of wind direction and speed over the observation area

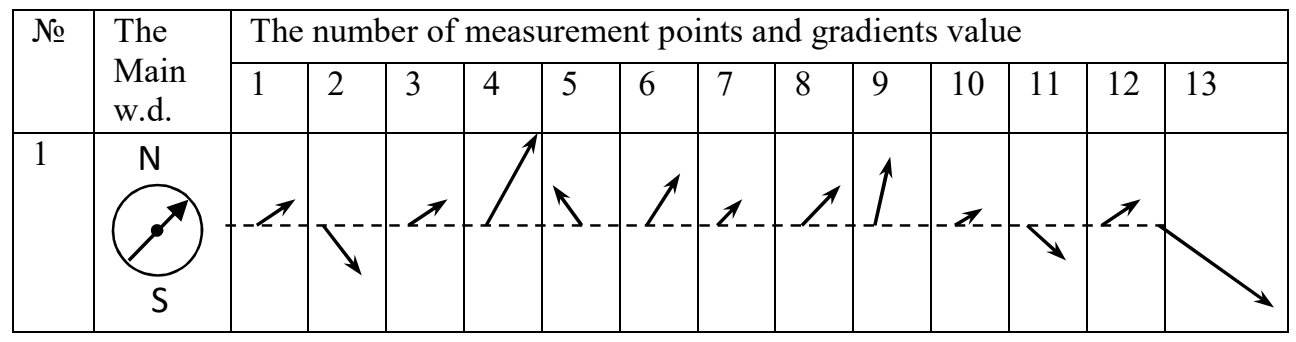

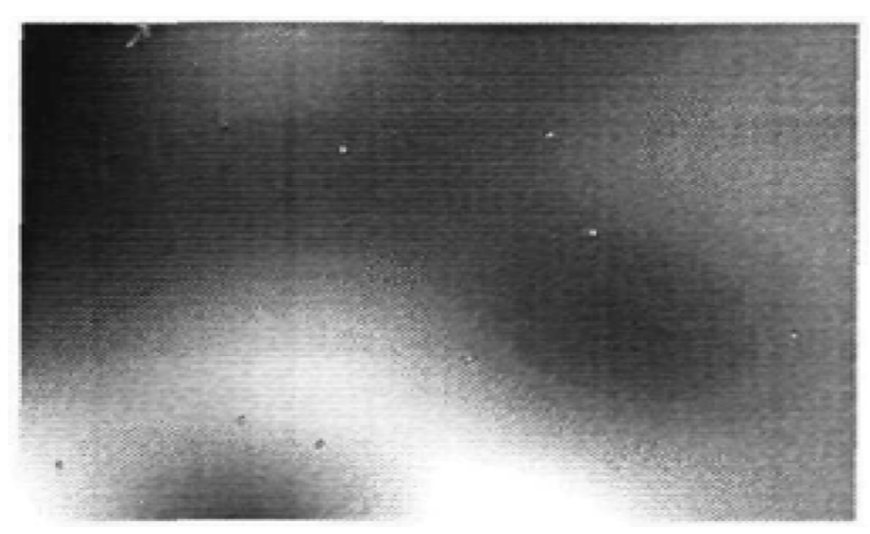

Fig.3. The picture shows the vertical component value recunstructing of wind direction and speed vector on the basis of defining measurements.

Bright fields mean the maximum value

Dark fields mean the minimum value of the vertical component

To synthesize the air flow field model, the initial data obtained in the defining nodes in the form of velocity values $\mathrm{V}(\mathrm{x}, \mathrm{y})$ and wind directions $\mathrm{x}(\mathrm{x}, \mathrm{y})$ are converted into vertical and horizontal projections of velocity vectors $\Delta \mathrm{x}(\mathrm{x}, \mathrm{y})$ and $\mathrm{DX}(\mathrm{x}, \mathrm{y})$ (Fig. 5):

$$
\begin{gathered}
\Delta \mathrm{x}(\mathrm{x}, \mathrm{y})=\mathrm{V}(\mathrm{x}, \mathrm{y}) \cos (\mathrm{a}(\mathrm{x}, \mathrm{y})) \\
\Delta \mathrm{y}(\mathrm{x}, \mathrm{y})=\mathrm{V}(\mathrm{x}, \mathrm{y}) \sin (\mathrm{a}(\mathrm{x}, \mathrm{y}))
\end{gathered}
$$

The interpolation model of the air flow field includes two models of velocity vector projections in defining nodes: 


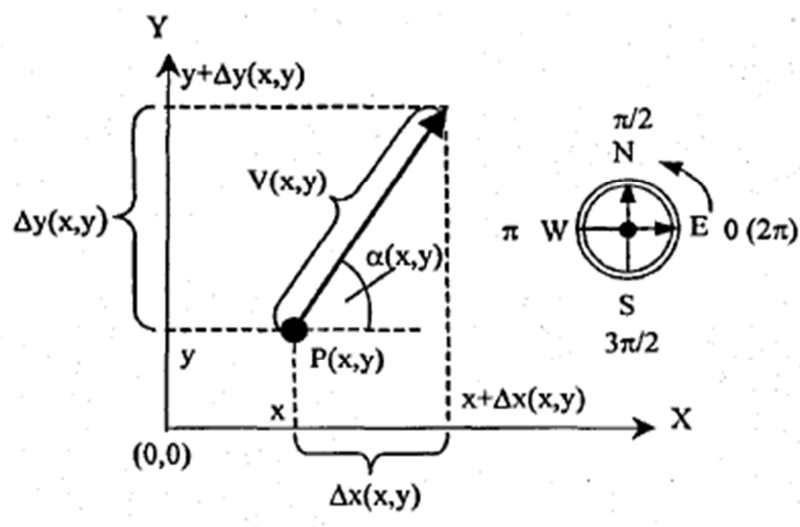

Fig. 4. The speed vector resolution at defining point $P(x, y)$

$$
\left\{\begin{array}{l}
\Delta \hat{x}(x, y)=\sum_{K=0}^{M-1} \hat{a}_{x, k} \cdot \varphi_{k}(x, y) \\
\Delta \hat{y}(x, y)=\sum_{K=0}^{M-1} \hat{a}_{y, k} \cdot \varphi_{k}(x, y)
\end{array}\right.
$$

$\varphi_{k}(x, y)$ - the first basic functions from the full orthogonal system;

$\hat{a}_{x, k}, \hat{a}_{y, k}-$ the amplitude estimate for harmonics in the appropriate simulated projection

The choice of new harmonics and their amplitudes ax, k, ay, $\mathrm{k}$ are estimated taking into account the defining measurements errors according to the actual defining plan which is based on the stochastic interpolation method in the evolutionary mode. With the gas cloud of harmful substances spreading, it is important to inform on its direction and speed on time. That is why the program that calculates the gas cloud movement at technologyrelated accidents was created. The initial values for the calculation are the following: Roshydromet informs on the wind direction and speed in defining points of the studied area and Civil Defense Services for Emergency Situations reports the location and characteristics of emission. If there is a change of the current wind speed and direction values during the gas cloud movement, the forecast is updated by entering new values of wind direction and speed, querying the database of plots, selecting them, calculating the dynamics of the gas cloud movement. To calculate the gas cloud movement given the technology-related accident the values of direction and wind speed are entered into the special program to calculate the the gas cloud movement, the plot of air flow is selected (11) it should closely corresponds to the wind direction and speed at the defining nodes. On the basis of the selected plot, the field of the gas cloud spreading is calculated and a shortterm forecast is set (Fig.4). The projecting method of polluting cloud motion is based on its representation by a large number of points - elementary volumes of gas. There are two types of motion for each point:air flow moving and diffusion [6].

The air flow moving is determined by the field of its distribution, represented by the certain projecting models (2). The gas particles diffusion is modeled on the basis of Fick's first law [8]. It claims that the amount of the diffused substance is proportional to the gradient concentration. To calculate the diffusion, a grid of 8 plot elements is used. These elements are adjacent to the certain volume point elements (Fig.7). We use the following heuristic algorithm to calculate the diffusion: for each point displacements are determined and due to the different concentration between the grid 1 central element and its neighboring element, as well as a random displacement that is proportional to the concentration in the current chamber [6]:

$$
\Delta \mathrm{xd}=k x x^{*} N_{2}+k x^{*} N_{9}+k x x^{*} N_{3}-k x x^{*} N_{4}-k x^{*} N_{5}-k x x^{*} N_{6}-f x^{*} N_{1},
$$




$$
\Delta y d=\text { kyy }^{*} N_{2}+k y^{*} N_{3}+\text { kyy }{ }^{\prime} N_{4}-k y y^{*} N_{6}-k y^{*} N_{7}-k y y^{*} N_{8}-f y^{*} N_{1},
$$

где $N_{1}, N_{2} \ldots N_{9}$ - The number of points from the1,2 ..9 squares;

$k x x$ и $k y y$-Diffusion coefficients for $\mathrm{x}$ and $\mathrm{y}$ axes;

$f x$ и $f y$-Random diffusion coefficients from the square 1 along the $\mathrm{x}$ and $\mathrm{y}$ axes;

Thus, we get the new point position value.

$$
X_{n+1}=X_{n}+\Delta \mathrm{x}+\Delta \mathrm{x} d ; Y_{n+1}=Y_{n}+\Delta y+\Delta y d
$$

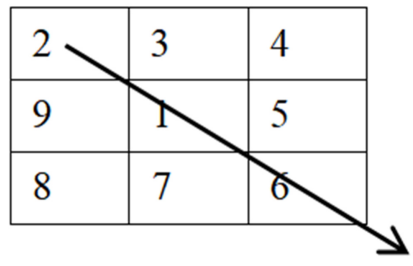

Fig.5. The grid for calculating the gas cloud particles diffusion Results

57 surveys of the area under different weather conditions were conducted during the experimental study. These are some obtained results:

Table 3. Indications of wind direction and speed in the observation area

\begin{tabular}{|l|l|l|l|l|l|}
\hline \multirow{2}{*}{$\begin{array}{l}\text { The } \\
\text { number } \\
\text { of } \\
\text { experim } \\
\text { ents }\end{array}$} & $\begin{array}{l}\text { Prevalent } \\
\text { wind } \\
\text { direction }\end{array}$ & \multicolumn{3}{|l|}{ Wind speed $\mathrm{m} / \mathrm{s} /$ wind direction in degrees } \\
\cline { 3 - 6 } & № 1 & $\begin{array}{l}\text { Station } \\
\text { № 2 }\end{array}$ & $\begin{array}{l}\text { Station } \\
\text { № 3 }\end{array}$ & $\begin{array}{l}\text { Defining } \\
\text { point in the } \\
\text { industrial } \\
\text { area }\end{array}$ \\
\hline 1. & $\mathrm{~N}\left(0^{\circ}\right)$ & $1,3 / 0$ & $1,3 / 0$ & $1,2 / 2$ & $2 / 25$ \\
\hline 2. & $\mathrm{NE}\left(45^{\circ}\right)$ & $1,6 / 40$ & $1,7 / 35$ & $1,7 / 45$ & $2 / 60$ \\
\hline 3. & $\mathrm{E}\left(90^{\circ}\right)$ & $0,5 / 105$ & $0,6 / 100$ & $0,6 / 100$ & $1 / 110$ \\
\hline 4. & $\mathrm{SE}\left(135^{\circ}\right)$ & $2,7 / 140$ & $2,7 / 135$ & $2,8 / 140$ & $3 / 170$ \\
\hline 5. & $\mathrm{~S}\left(180^{\circ}\right)$ & $2,5 / 180$ & $2,3 / 180$ & $2,0 / 195$ & $4 / 240$ \\
\hline 6. & $\mathrm{SW}\left(225^{\circ}\right)$ & $3,0 / 240$ & $3,5 / 225$ & $3,1 / 225$ & $5 / 165$ \\
\hline 7. & $\mathrm{~W}\left(270^{\circ}\right)$ & $2,5 / 265$ & $2,5 / 260$ & $2,6 / 270$ & $3 / 240$ \\
\hline 8. & $\mathrm{NW}\left(315^{\circ}\right)$ & $0,3 / 310$ & $0,3 / 110$ & $0,4 / 310$ & $1 / 320$ \\
\hline
\end{tabular}

The data of four stations FRC «Atmosfera» that analyse air pollution using five main chemicals as well as four standing laboratories of Roshydromet "Station - 2» which are located in the residential area of the city fail to show an accurate picture of the air over the industrial cluster. 


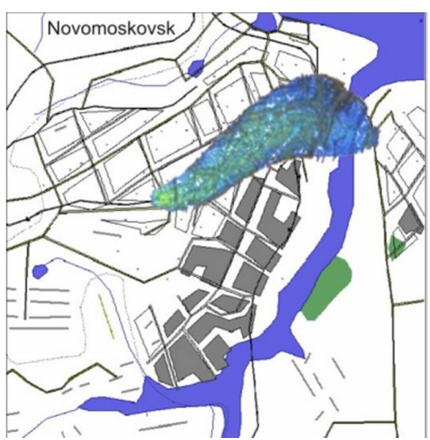

a)

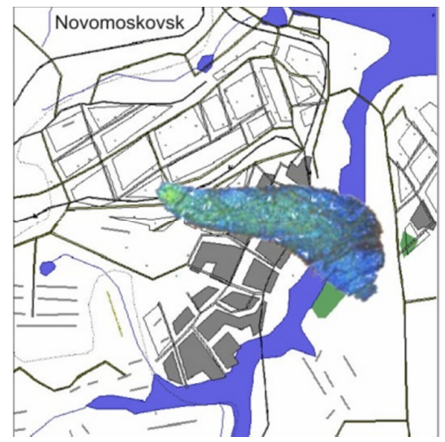

b)

Fig.6. The projection of the gas cloud movement with the diffusion coefficient 0,03 in quiet southwest wind $(1,7 \mathrm{~m} / \mathrm{s})$ after 40 minutes a) The station's data, b) Defining measurements of meteorological data

That is, the data of atmospheric air measurement in the district are groundless and halfbaked. Thus, in case of technology-related accident with the highly toxic substances emission, Civil Defense Services and Services for Emergency Situations will fail to project the accident's implications, taking into account the size and movement of the gas cloud. Therefore it can lead to environmental disaster [10].

\section{Discussion}

These results show that when choosing the monitoring station location for the air conditions, it is relevant to analyze the impact of the terrain on the air flows movement.

Today the new station's equipment of FRC "Atmosfera" (Station No. 5) in Zavodskoy district is the burning issue, because it's located near the industrial part of the city, which is one of the ways of FRC "Atmosphere" modifying. With air pollution monitoring station near the sanitary protection zone of organizations will help to uncover negative environmental factors on time.

The search for an ideal location of the station No.5 is another reason of this study developing. Thus, the method of initial monitoring nodes rational scheme synthesis was used. At the same time, to make this method effective, it is important to provide statistics on the state of air flows. This data should be obtained from specially organized full-scale measurements in the nodes of a uniform grid of proper size.

\section{Conclusion}

With growing industry it is important to improve air monitoring systems in residential areas. It is indeed important for the large industrial center - Novomoskovsk The ecomonitoring system of Novomoskovsk fails to perform tasks properly. Stationary Roshydromet and FRC «Atmosfera» stations are located in the residential area of the city. It is far away from the main industrial district, where a lot of chemical factories are situated. The article is aimed to figure out whether the current monitoring stations provide compelling data of the air basin over the industrial area. The research involved the interpolation method of air movement control over areas which have a mixed landscape because of technology-related accidents. The obtained results show that ecomonitoring stations' data is bad-grounded. Thus, in case of technology-related accident with the highly toxic substances emission Civil Defense Services and Services for Emergency Situations 
will fail to project severe implications. Therefore, it is important to modify current ecomonitoring system of Novomoskovsk to define all negative environmental factors on time. Yet it is relevant to pay attention to prevalent wind direction and area landscape impact on the air movement when choosing a new station.

\section{References}

1. A.V. Gluhov, M.A. Krivova, N.G.Yagovkin, NSSC RAS, 1-9 (2010)

2. B.N. Duncan, J.G., 976-996 (2016)

3. L. Flynn, G.R., (2014)

4. I.M. Abutu, U.J. Imeh, T.M. S Abdoulie, A.E. Adewale, M.M. Bashir, IJCNIS, 6, 6875 (2018)

5. J.N. Vershinin, A.A. Bykov, V.N. Krutikov, V.V. Meshechkin, JKemGU, 1 (2014)

6. Y.I. Belyaev, D.P. Vent, Y.V. Gerber, O.N. Veprentseva, K.P. Latyshenko CPE 7, 491-494 (2009)

7. M. Qiu, C. Huang, IJEME, 1, 47-50 (2011)

8. V.T.Kokoyev, V.A. Bocharov GIAB 12, 22-23 (2004)

9. H. Hatakenaka, HORIBA Technical Reports (2012)

10. Z. Benotmane, G. Belalem, A. Neki, IJIEEB, 5, 23-29 (2018)

11. U. Platt, Advanced Environmental Monitoring, 3-20 (2008) 